\title{
Conceptual Understanding on Magnetic Field Concept through Interactive Conceptual Instruction (ICI) with PDEODE*E Tasks
}

Article in Advanced Science Letters · February 2017

DOI: $10.1166 /$ asl.2017.7539

CITATIONS

2

5 authors, including:

\section{Achmad Samsudir}

Universitas Pendidikan Indonesia

52 PUBLICATIONS 17 CITATIONS

SEE PROFILE
READS

159

\section{Bayram Coştu}

Yildiz Technical University

35 PUBLICATIONS 385 CITATIONS

SEE PROFILE

Some of the authors of this publication are also working on these related projects:

Project

Interactive Simulation View project

Enhancing Junior High School Students Conceptual Understanding using The POE-based

Project Demonstration Technique on Static Electricity View project 
Copyright (C) 2017 American Scientific Publishers

All rights reserved

Printed in the United States of America
Advanced Science Letters

Vol.23,(2), 2017

\title{
Promoting Conceptual Understanding on Magnetic Field Concept through Interactive Conceptual Instruction (ICI) with PDEODE*E Tasks
}

\author{
Achmad Samsudin ${ }^{1}$, Andi Suhandi ${ }^{1}$, Dadi Rusdiana ${ }^{1}$, Ida Kaniawati ${ }^{1}$, Bayram Coştu ${ }^{2}$ \\ ${ }^{1}$ Department of Physics Education, Faculty of Mathematics and Natural Sciences Education, \\ Universitas Pendidikan Indonesia, Bandung 40154, Indonesia \\ ${ }^{2}$ Science Education Program, Faculty of Education, Yildiz Technical University, Istanbul 34210, Turkey
}

\begin{abstract}
We constructed Interactive Conceptual Instruction (ICI) model through PDEODE*E tasks (stands for Predict, Discuss, Explain, Observe, Discuss, Explore*, and Explain) for promoting the pre-service physics teachers' understanding on magnetic field. The ICI model consists of four phases; 1) Conceptual focus 2) Use of texts 3) Research-based materials (PDEODE*E tasks) 4) Classroom interactions. The ICI of teaching model has been implemented to seven Physics students who were re-taking (take the course for second times) in the Basic Physics II course as a pilot study. A Field Conceptual Change Inventory (FCCI) comprised of 15 three-tier test items was administered to seven pre-service physics teachers. Students' ideas were elicited by using FCCI and students' worksheets regarding PDEODE*E tasks. The test and worksheet were analyzed in qualitative way. An analysis of collected data has mainly focused on magnetic field conceptions with its subordinate concepts such as magnetic interaction in variety of mediums, magnetic swing (Lorentz law) and rotating magnetic field (Eddy's current). This study concluded that the students' conceptual understanding of the magnetic field increases but a few misconceptions still occurred in seven students' minds.
\end{abstract}

Keywords: PDEODE*E tasks, Interactive Conceptual Instruction (ICI) model, conceptual understanding, misconception, pre-service physics teachers.

\section{INTRODUCTION}

The POE teaching model has probed students' understanding by requiring students to carry out three tasks. Firstly, students predict the outcome of event and justify their prediction (P: Predict). Secondly, they describe what they see (O: Observe). Finally, students reconcile any discrepancy between prediction and observation (E: Explain) ${ }^{1,2}$.

*Email Address: achmadsamsudin@upi.edu

Based on the POE, Savander-Ranne \& Kolari ${ }^{3}$ has been developed PDEODE teaching model. They utilized PDEODE teaching model upon vocational school students with open-ended worksheets. Afterwards, this model has been widely utilized to enhance students' understanding of considered concepts (e.g., Coştu ${ }^{2}$ ).

Differences of the between POE and PDEODE is adding "Discussion (D)" phase into POE. As described by Coştu", adding to "D" into POE supplies students for creating an academic atmosphere that supports discussion sessions, and a diversity of views. PDEODE is consisted 
of six steps. In the first step (P: Prediction), the lecturer offered a conceptual phenomenon to students by using worksheet and requested them to predict individually as to what should occur, and to validate their thinking. In the second step (D: Discuss), this step's purpose was that the students are able to discuss and share their thinking in their groups. In the third step (E: Explain), students in each group investigated to grasp a compromise and conclusion about phenomenon, and to present their ideas to other groups through whole-class discussions. Subsequently, the students again worked in their groups to accomplish a hands-on experiment and individually documented their observations about what occurred. In this step (O: Observe), the students observed "changes" in the phenomenon and the lecturer lead them to focus on observations that relevant to the targeted concepts. In the fifth step (D: Discuss), the students were requested to reconcile their predictions with the genuine observations made in the earlier step. Here, the students were asked to analyze, compare, contrast, and criticize with their classmates in their groups. In the last step (E: Explain), the students confronted all discrepancies between observations and predictions. At this point, the students had to attempt and determine any contradictions. The role of the lecturer in this teaching strategy was to challenge students and to assist students' discussions. A short time ago, in the literature (e.g., Samsudin, Suhandi, Rusdiana and Kaniawati ${ }^{4}$ ), we have been enlarged PDEODE model as PDEODE*E by adding "Explore (E*)" phase to be more useful especially to provide conceptual change and to enhance conceptual understanding of physics students. We also implemented PDEODE*E model to seven preservice Physics teachers in the university level as a pilot study. Adding $\mathrm{E}^{*}$ into PDEODE, we aimed to eliminate a few disadvantages and to empower of PDEODE teaching model. Tell openly, PDEODE cannot facilitate the students to explore the concept deeper and more comprehensive way. Also, PDEODE is not able to analyze, synthesize, and infer relationships between concepts both qualitatively and quantitatively without exploration phase ( $\mathrm{E}^{*}$ phase). We state that $\mathrm{PDEODE}^{*} \mathrm{E}$ based teaching model was more powerful in order to promote conceptual change; hence, we used this model accurately. Correspondingly, we utilized exploration sheet separately to explore magnetic concepts in order to change students' misconceptions towards scientific conceptions properly.

The model, ICI model with PDEODE*E tasks, we have implemented in this study consists of four phase; 1) Conceptual focus 2) Use of texts 3) Research based materials (PDEODE*E tasks) 4) Classroom interactions.

\section{METHODS}

Participants who were involved in this research were seven pre-service physics teachers (four boys and three girls, whose ages were around 21 years-old). They were originated from different towns and re-enrolled in Basic Physics II courses as Education University (a pseudonym).
The first phase (Conceptual Focus); takes account of lecturer's activities: explaining learning objective, showing physics phenomena through simulation and/or animation which were obtained from computer multimedia ${ }^{5}$, and motivating students to participate actively during the learning process. The second phase (Use of Texts); involves lecturer's activities: asking students to learn textbooks or e-books then asking them to construct concept map related to concept that they have learned. The third phase (Research Based Materials); includes lecturer's activities: asking students to make a group consists of three to four students, encouraging students to collect the information which is needed in order to analyze experimental result of $\mathrm{PDEODE}^{* \mathrm{E}}$ worksheet and supervising the students to explore according to their conceptions' level with an exploration sheet. The fourth phase (Classroom Interactions); involves lecturer's activities: observing students' discussion in each groups and helping the students to solve their problems via confronting the exploration sheet As it can be seen from the model, PDEODE* $\mathrm{E}$ tasks plays only a part in the third phase because this phase requires some research analysis for the students. This is intended that the model was assumed as a "place" for $\mathrm{PDEODE}^{*} \mathrm{E}$ tasks to become an instrument in term of changing the students' misconceptions and enhancing students' conceptual understanding.

In this article, researchers focused on magnetic concepts, particularly the concepts about magnetic interaction in various mediums, magnetic swings (Lorentz law) and rotating magnetic field (Eddy's current). The concept of magnetic field is very important for students for being "back-bone" of the magnetic concepts. Furthermore, this concept is very necessary to be learned by pre-service physics teachers because the concept of magnetic field is very abstract and complex (e.g., Dori \& Belcher ${ }^{6}$; Cheng, Lin, Chang, Li, Wu, \& Lin ${ }^{7}$ ). Magnetic field concepts have been achieved through ICI model which constituted to experimental exploration which was guided by various learning sources such as text books, multimedia-computer, and material in the form of conceptual change text, which has been described in the previous paragraph. On that account, it was expected that pre-service physics teachers showed a sound understanding about magnetic field and related to the concepts.

The purpose of this study was to develop the ICI model with PDEODE*E tasks that be able to promote conceptual change and to analyze qualitative changes among pre-service physics teachers' understanding on magnetic field.

The subject was directly involved from a small class as a pilot study and all students participated in the research voluntarily. One of the students did not take to the posttest but this student took the pre-test, and two other students took the post-test but they did not take the pre- 
test (the three students were dropped from analysis). The duration of the course was four 50-minutes periods.

In order to analyze students' conceptions, we utilized Field conceptual Change Inventory (FCCI) on magnetic field concepts. The instrument test items consisted of fifteen questions that form in three-tier test items (in detail, the first-tier was multiple-choices, the second-tier was reasons regarding the first-tier and the third-tier was students' confidence scale). The ICI model with
PDEODE*E tasks was analyzed via qualitative way by using students' codding (e.g., S1, S2, S3, ... etc.) and misconceptions' codding (e.g., M1, M2, M3, ... etc.). We have also categorized the conceptual change process in to positive and partial-positive change $(+)$, negative change (-) and no change (0). Furthermore, students' conceptual change was qualitatively analyzed in the three categories for instances acceptable change (A), Not Acceptable change (NA) and No change (NC).

\section{RESULTS AND DISCUSSIONS}

The results from the three-tier test items are presented in Table 1. Since a few students (namely; S1, S6, and S7) absent from the pre- or post- tests (as detailed in the Table 1), they were completely extracted from the analyzing procedure.

Table.1. Students' responses in each criterion and their changes from pre- to post-tests.

\begin{tabular}{|c|c|c|c|c|c|c|c|c|}
\hline \multirow{2}{*}{ No. } & \multicolumn{2}{|c|}{ Understanding (U) } & \multicolumn{2}{|c|}{ Misconceptions (M) } & \multicolumn{2}{|c|}{$\begin{array}{l}\text { No Understanding } \\
(\mathrm{NU})\end{array}$} & \multicolumn{2}{|c|}{ Partial Understanding (PU) } \\
\hline & Pre-test & Post-test & Pre-test & Post-test & Pre-test & Post-test & Pre-test & Post-test \\
\hline 1 & $\mathrm{~S} 2, \mathrm{~S} 3, \mathrm{~S} 4$ & $\mathrm{~S} 2, \mathrm{~S} 3, \mathrm{~S} 4, \mathrm{~S} 5$ & - & - & - & - & S5 & - \\
\hline 2 & S5 & S5 & S2 & - & - & S2 & S3, S4 & S3, S4 \\
\hline 3 & - & S5 & S2 & S2 & S3, S5 & $\mathrm{S} 3, \mathrm{~S} 4$ & S4 & - \\
\hline 4 & S3 & S3 & - & - & S4 & - & $\mathrm{S} 2, \mathrm{~S} 5$ & $\mathrm{~S} 2, \mathrm{~S} 4, \mathrm{~S} 5$ \\
\hline 5 & - & - & $\mathrm{S} 3, \mathrm{~S} 4, \mathrm{~S} 5$ & S4 & S2 & - & - & $\mathrm{S} 2, \mathrm{~S} 3, \mathrm{~S} 5$ \\
\hline 6 & - & - & - & - & S3 & S3 & $\mathrm{S} 2, \mathrm{~S} 4, \mathrm{~S} 5$ & $\mathrm{~S} 2, \mathrm{~S} 4, \mathrm{~S} 5$ \\
\hline 7 & - & - & S3 & S3 & $\mathrm{S} 2, \mathrm{~S} 4, \mathrm{~S} 5$ & S2 & - & S4, S5 \\
\hline 8 & - & - & S2, S3 & S3 & S4, S5 & - & - & $\mathrm{S} 2, \mathrm{~S} 4, \mathrm{~S} 5$ \\
\hline 9 & S2 & S2, S5 & - & - & S3 & - & $\mathrm{S} 4, \mathrm{~S} 5$ & S3, S4 \\
\hline 10 & - & $\mathrm{S} 4$ & - & - & $\mathrm{S} 2, \mathrm{~S} 5$ & S3, S5 & $\mathrm{S} 3, \mathrm{~S} 4$ & S2 \\
\hline 11 & - & - & $\begin{array}{l}\text { S2, S3, S4, } \\
\text { S5 }\end{array}$ & $\mathrm{S} 2$ & - & - & - & $\mathrm{S} 3, \mathrm{~S} 4, \mathrm{~S} 5$ \\
\hline 12 & - & - & $\mathrm{S} 2, \mathrm{~S} 3, \mathrm{~S} 5$ & $\begin{array}{l}\text { S2, S3, } \\
\text { S5 }\end{array}$ & S4 & - & - & S4 \\
\hline 13 & - & - & S2, S5 & - & S3, S4 & $\mathrm{S} 2, \mathrm{~S} 4$ & - & S3, S5 \\
\hline 14 & - & & $\mathrm{S} 3$ & - & S4, S5 & $\mathrm{S} 2, \mathrm{~S} 4$ & S2 & S3, S5 \\
\hline 15 & - & $\mathrm{S} 2, \mathrm{~S} 3, \mathrm{~S} 5$ & - & S4 & $\mathrm{S} 2, \mathrm{~S} 4, \mathrm{~S} 5$ & - & S3 & - \\
\hline
\end{tabular}

Note: $S 1, S 2, S 3 \ldots$ refer to the particular students in the study

As seen from the Table 1, most of the changes were in the positive ways. For instance, a number of the students have given responses that were classified in the understanding (U) and partial understanding (PU) categories dramatically increased after the ICI model intervention. Similarly, the Table 1 reveals mostly positive conceptual changes, that is, a number of the students have given responses that were classified in the misconceptions (M) category dramatically decreased after the ICI model intervention. This means that the students changed their misconceptions towards scientific conceptions. On the other hand, only one example $\left(6^{\text {th }}\right.$ three-tier test item), students' responses were not changed over time. This means that ICI teaching model was inefficient to change students' conceptions. Main reason 1207 of this issue should be that researchers had a limitation problem related to the equipment about a bubble chamber. Hence, pre-service physics teachers could not analyze the trajectory of a particle movement based on that experiment. Similar result could be seen in the conceptual change studies (e.g. Coştu ${ }^{8}$; Srivastava, John, Gosling \& Potter $^{9}$; Dass $^{10}$ ).

Since the main research problem was to determine whether or not students' misconceptions changed towards to scientific conceptions, the "Misconceptions (M)" category in the Table 1 has explained in detail. Students' responses were further analyzed in order to unveil their misconceptions based on three-tier test (FCCI) items of pre- and post- tests. These are presented in Table 2. 
Table.2. Students' misconceptions regarding magnetic field and their changes from pre- to post-tests.

\begin{tabular}{lll}
\hline${\text { Students' Misconceptions }(\mathrm{M})^{\mathrm{a}}}^{\text {a Pre-Test }}$ & $\begin{array}{l}\text { Post- } \\
\text { Test }\end{array}$ & $\begin{array}{l}\text { Conceptual changes } \\
\text { from pre-test to } \\
\text { post-test }\end{array}$ \\
\hline
\end{tabular}

$\mathrm{M} 2^{\mathrm{b}}$ : The orientation of compass direction is

S2

Positive (†)

considered to be only influenced by earth's

magnetic field neither is influenced by the closest

and the biggest magnetic field surrounding it.

M3: The force which acts to a moving-charged

object in the uniformed-magnetic field is

S2

S2 No change (0)

considered to be any other forces that act on them be side magnetic force.

M5: The work which acts to a moving-charged object in the uniformed-magnetic field is not considered to be null.

M7: A moving-charged object in the uniformedmagnetic field is not considered to be correlated with cross-product between two vectors, that is, a movement direction and a field direction.

M8: Magnetic forces at several positions in the uniformed-magnetic field with different angles are considered to be different.

M11: A stationary charged-object in the uniformed-magnetic field is considered to be acted by force as in the electric field concept.

M12: The current's direction of a moving-negative charged object in the uniformed-magnetic field is considered to be same as a moving-positive charged object.

M13: The orientation of magnetic field direction in the surrounding two electric wires is not considered to be correlated with the computation of vector fields.

M14: The interaction a moving-charged object with different angles is considered to be same whereas is not same based on vector crossproduct.

M15: The magnetic field which is caused by the electric-charged on the straight-wire is not $\mathrm{S} 3, \mathrm{~S} 4$ S4 Partial positive $(†)$ S5

S3 No change (0)

\section{S2, S3 S3 Partial positive (†)}

S2, S3, S2 $\quad$ Partial positive $(†)$

S4, S5

S2, S3, S2, S3, No change (0)

S5 S5

S2, S3, No change $(0)$
S5

S2, S5 - Positive (†) considered to be influenced by the position of its review.

\footnotetext{
Note: ${ }^{a}$ Number 2 in the M2 (Misconception 2)

${ }^{\mathrm{b}}$ A few misconceptions (e.g. M1) were not seen in the table because of lacks of students' minds based on three-tier test items.
}

As seen from the Table 2, most of the changes in pre-service physics teachers' misconceptions were affirmative (positive or partial positive). That is, a number of the students held misconceptions decreased dramatically after the ICI intervention (M2, M5, M8, M11, M13 and M14).This means that the students have changed their misconceptions towards scientific conceptions. Conversely, the Table 2 reveals only one conceptual change was unfavorable way, that is, student (coding as S4) held misconception (M15) after the intervention even though the student did not have misconception before the intervention. This case regarding M15 has been seen only one student. This was originated from that only one student, from the participated students, did not actively involve not only exploration sheet but also the instruction. Moreover, the student should be experienced group partner/s' misconception/s and be influenced and finally accepted their misconception/s. This issue was noticed by the first author of the paper in especially discussion phase of 
PDEODE*E tasks. Another reason possibly was generated from students' views or perspectives. That is, students who remembered the words of the concept did not required sound understanding related to the concept. This reason was dealt with Tuberty, Dass, \& Windelspecht ${ }^{11}$. We concluded that the student seems to understand the confusion between scientific theories and the day to day used of the word theory, this student still held her common misconception that laws are absolute.

The Table 2, interestingly, also shows that students' misconceptions did not change after the intervention (M3, M7 and M12). Many studies on conceptual change (e.g.
Safadi \& Yerushalmi $^{12} ;$ Leppavirta $^{13} ; \quad$ Engström, Gustafsson, \& Niedderer ${ }^{14}$; Çalık, Ayas, \& Coll $^{15}$; Aufschnaiter ${ }^{16}$; Friege \& Lind $^{17}$; Vosniadou ${ }^{18}$ ) stated that conceptual change is a time consuming process because misconceptions are well embedded in students' earlier mind schema.

Based on the data which have been presented in the Table 1, possible types of changes from the pre-test and the post-test could were constructed and given a few sample of students' responses (see Table 3) in each categories.

Table.3. A few examples of possible types of changes in criterion of students' responses based on Table $1 *$.

\begin{tabular}{|c|c|c|c|c|}
\hline $\begin{array}{l}\text { Change' } \\
\text { category }\end{array}$ & $\begin{array}{l}\text { Pre- } \\
\text { test }\end{array}$ & $\rightarrow$ & $\begin{array}{l}\text { Post- } \\
\text { test }\end{array}$ & An example of students' conceptions in each categories \\
\hline
\end{tabular}

Acceptable $\quad 1 \mathrm{M} \rightarrow \mathrm{PU}$

(A)

$\mathrm{T} \rightarrow \mathrm{PU}$

$\begin{array}{llll}\text { Acceptable } & 1 \mathrm{M} & \rightarrow & \mathrm{NU} \\ \text { (NA) } & & & \end{array}$

No Change $\quad 1$ PU $\rightarrow$ PU
(NC)
S2 for no. 8: "At the pre-test, $S 2$ considered that the difference in the horizontal field, angle's direction of a movement of positive electric charged objects around a uniformed-magnetic field are considered influential on the magnetic force experienced by these objects. After utilizing treatment, understanding the concept began to grow and when the post-test S2 answered correctly on the first tier was the horizontal field angle direction has no effect on the magnetic force. But the answer to the second tier one which S2 considered only $90^{\circ}$ angle formed, so that, if the object that move into the area of the magnetic field should obtained a greater force than the particle 1 and $2 "$.

S2 for no. 2: "S2 thought that when the pre-test with a very confident rating of misconception about the orientation of compass direction was considered to be only influenced by earth's magnetic field neither was influenced by the closest and the biggest magnetic field surrounding it, when the post-test in tier three, S2 chose "not sure" of the answer".

S3 for no. 2: "S3 thought that while the pre-test and post-test on unsurely choosing about the orientation of compass direction was considered to be only influenced by earth's magnetic field neither was influenced by the closest and the biggest magnetic field surrounding it, so there was no conceptual change in his mind so there was no change for S3".

\section{Note:}

1) $S 2$ and $S 3$ refer to the particular students' number 2 and 3 in the study

2) M, NU and PU stand for Misconceptions, No Understanding and Partial Understanding, respectively (see Table 1)

The changing processes were divided into three categories in order to facilitate researchers in analyzing conceptual change that occurred in the pre-service physics teachers' minds. As seen from the Table 3, three types of possible changes were observed in each change category (A, $\mathrm{NA}$ and NC). In the "A" category, students' understanding on "Magnetic Field" changed from pre-test to the post-test with some improvement. That is, students' understanding enhanced as a result of the ICI model. Interestingly, in the "A" category, while students' responses in misconception (M) criterion changed as partial understanding category, they did not change as understanding (U) criterion. This means that misconceptions are resistant to change and that conceptual change is a time consuming process as given in the plethora of earlier researchers (e.g., Vosniadou ${ }^{2,18}$ ).

As for "NA" category, students' understanding changed from pre-test to the post-test in unfavorable ways. For example, $2^{\text {nd }}$ changes, S2 student' responses in understanding (M) criterion changed as no understanding (NU) category. Similarly; while S2 hold misconception in the pre- test section, she changed her response to no understanding (NU) category. This change, especially seen in a case of S2's understanding, is very unfavorable change.

As for "NC" category, students' understandings were not 
changed from pre-test to the post-test. We mainly aimed, in this study, to be changed students' misconceptions towards scientific conceptions. However; students' misconceptions did not changed from pre- to post-tests after the intervention.

\section{CONCLUSIONS AND SUGGESTIONS}

To sum up, this research proved that the ICI model with $\mathrm{PDEODE}^{*} \mathrm{E}$ tasks utilized were effective in changing students' misconceptions and enhancing students' conceptual understanding. Moreover, the ICI model with PDEODE*E tasks indicated that it was possible to change the traditional classroom setting in terms of ease conceptual change. Nonetheless, many multifarious factors such as: cognitive, motivational, ontological, and epistemological affected conceptual change process (e.g. Havu-Nuutinen ${ }^{19}$ ). Based on this thoughtfulness, it is possible to utilize our model in teaching magnetic field concepts by focusing on problem about group discussion given earlier.

Lastly, we suggest here that the success of the preservice physics teachers was mainly arisen from the fact that the PDEODE*E tasks helped them to evaluate their prior knowledge and to re-check their ideas within their groups or whole-class's discussions and to construct new concept in their minds especially by using exploration sheet known as conceptual change model proposed by Posner, Strike, Hewson, \& Gertzog 5, 8, 20. Hence, we suggest that ICI model with PDEODE*E tasks should be utilized to promote conceptual change.

\section{ACKNOWLEDGMENTS}

We special say thank to Asep Dedy Sutrisno as research assistant and all participants who participated in this research. This work was supported in parts by "Hibah Disertasi Doktor", "Sandwich-like/PKPI program" and "Hibah Bersaing" DIKTI under Grant year 2015-2016.

\section{REFERENCES}

[1] R. Gunstone, R. White. Understanding of gravity. Science Education, 65(3) (1981) 291-299.

[2] B. Coştu, A. Ayas, M. Niaz. Promoting conceptual change in first year students' understanding of evaporation. Chemistry Education Research and Practice, 11(1) (2010) 5-16.

[3] C. Savander-Ranne, S. Kolari. Promoting the conceptual understanding of engineering students through visualization. Global Journal of Engineering Education, 7(2) (2003) 189-199.

[4] A. Samsudin, A. Suhandi, D. Rusdiana, I. Kaniawati. The PDEODEE students' worksheet on static electricity: as innovations in learning sets of physics. International Conference of Educational Research and Innovation, (2015) May 6-7; Yogyakarta, Indonesia

[5] A. Samsudin, A. Suhandi, D. Rusdiana, I. Kaniawati. Preliminary Design of ICI-based Multimedia for Reconceptualizing Electric Conceptions in Universitas Pendidikan Indonesia. Submitted to Institute of Physics (IOP) conference
This case should seem as conceivable, because students' misconceptions are deeply rooted into their existing knowledge structures $9,10,1$.

proceeding (2016).

[6] Y.J. Dori, J. Belcher. How does technology-enabled active learning affect undergraduate students' understanding of electromagnetism concepts?. The Journal of the Learning Sciences, 14(2) (2005) 243-279.

[7] M.F. Cheng, J.L. Lin, Y.C. Chang, H.W. Li, T.Y. Wu, D.M. Lin. Developing explanatory models of magnetic phenomena through models of magnetic phenomena through model based inquiry. Journal of Baltic Science Education, 13(3) (2014) 351-360.

[8] B. Coştu, A. Ayas, M. Niaz. Investigating the effectiveness of a POE-based teaching activity on students' understanding of condensation. Instructional Science, 40 (1) (2012) 47-67.

[9] S. Srivastava, O.P. John, S.D. Gosling, J. Potter. Development of personality in early and middle adulthood: set like plaster or persistent change?. Journal of Personality and Social Psychology, 84(5) (2003) 1041-1053.

[10] PM Dass. Understanding the nature of scientific enterprise (NOSE) through a discourse with its history: the influence of an undergraduate 'history of science' course, International Journal of Science and Mathematics Education, 3 (2005) 87-115.

[11] D.M. Tuberty, P. Dass, M. Windelspecht. Student understanding of scientific hypotheses, theories \& laws: exploring the influence of a non-majors college introductory biology course. International Journal of Biology Education, 1(1) (2011) 23-44.

[12] R Safadi, E Yerushalmi. Problem solving vs. troubleshooting tasks: the case of sixth-grade students studying simple electric circuits, International Journal of Science and Mathematics Education, 12 (2013) 1341-1366.

[13] J Leppavirta. Assessing undergraduate students' conceptual understanding and confidence of electromagnetics, International Journal of Science and Mathematics Education, 10 (2011) 10991117.

[14] S Engström, P Gustafsson, H Niedderer. Content for teaching sustainable energy systems in physics at upper secondary school, International Journal of Science and Mathematics Education, 9 (2010) 1281-1304.

[15] M Çalık, A Ayas, RK Coll. Enhancing pre-service elementary teachers' conceptual understanding of solution chemistry with conceptual change text, International Journal of Science and Mathematics Education, 5 (2011) 1-28.

[16] CV Aufschnaiter. Process based investigations of conceptual development: an explorative study, International Journal of Science and Mathematics Education, 4 (2006) 689-725.

[17] G Friege, G Lind. Types and qualities of knowledge and their relations to problem solving in physics, International Journal of Science and Mathematics Education, 4 (2006) 437-465.

[18] S. Vosniadou. Capturing and modeling the process of conceptual change, Learning and Instruction, 4 (1994) 45-69.

[19] S. Havu-Nuutinen. Examining young children's conceptual change process in floating and sinking from a social constructivist perspective. International Journal of Science Education, 27(3) (2005) 259-279.

[20] GJ Posner, KA Strike, PW Hewson, WA Gertzog. Accommodation of a scientific conception: toward a theory of conceptual change, Science Education, 66 (1982) 221-227.

Received: 22 March 2016. Accepted: 18 June 2016 